\title{
Converting an electronic calculator into a counter
}

\author{
ALLEN H. WOLACH, PETER ROCCAFORTE, and STEPHEN E. BREUNING \\ Illinois Institute of Technology, Chicago, Illinois 60616
}

\begin{abstract}
An inexpensive method for converting an electronic calculator into a digital counter is described. The conversion requires only two components in addition to the calculator (a relay and a capacitor).
\end{abstract}

Resettable counters are relatively expensive, slow, atnd noisy. Electronic calculators can be modified for use as six-or eight-digit counters (Alexandrovich, 1975). Many pocket calculators are now available for less than $\$ 15$. It is sometimes possible to buy broken electronic calculators for under $\$ 5$ that can still perform the functions necessary for a counter. The calculator-counter is generally faster, quieter, and less expensive than typical mechanical counters.

\section{Method}

Select a calculator with a constant addition provision. 'That is, entering a "l" and then operating the addition ("+") key (or " =" key in some calculators) for each additional tally continues to add 1 to the running total. This provision guarantees that a multiple entry will never occur when the calculator is converted into a counter; e.g., it is impossible to enter an 11 for a 1 . In addition, calculators are faster in the constant addition mode than in a mode where a number (in this case 1) and "+" are alternately entered. Some constant-addition calculators work in the sequence "clear," "1," "+," Additional depressions of the " + " key add 1 to the running total every tine the " + " key is depressed. Other calculators with constant addition provisions must be operated in the sequence "clear," "1," "+," " = " Additional depressions of the "=" key add 1 to the running total every time the " $=$ " key is depressed.

The keys on electronic calculators are switches. If wires are altached to the switch contacts, a relay's contacts (normally open and common) can be substituted for the switch closure. The keyboard for most calculators has wires printed on a tlexible insulating material that connects components in the calculator to the switches in the keyboard. It is not necessary to enter the sealed keyboard. Wires can be soldered to the printed wires on the flexible insulating strip.

Connect one of the two wires from the "+" key (" = " hey in some calculators) to the common and the other wire to the normally open of the $28-\mathrm{V}$ relay. Table 1 shous the wires coming out of the keyboard for the " + " or " =" keys on six representative

Table 1

Six Inexpensive Calculators Ranked in Order of Lase of Modification

\begin{tabular}{|c|c|c|c|c|c|c|}
\hline Brand & $\begin{array}{l}\text { Sequence of } \\
\text { Operation }\end{array}$ & Clear & ires 1 & cyboal & $=$ & \\
\hline Novus $650^{*}$ & Clear, $+, 1,+. c t c$ & 4.6 & 3,8 & 2,6 & & $\begin{array}{l}\text { National Semiconductor } \\
2900 \text { Semiconductor Way } \\
\text { Santa Clara. California }\end{array}$ \\
\hline lixactra $21^{*}$ & Clear $, 1,+$, elc. & 3.10 & 3.5 & 9.10 & & $\begin{array}{l}\text { Texas Instruments } \\
\text { P.O. Box } 22283 \\
\text { Dallas, Texas }\end{array}$ \\
\hline $\begin{array}{l}\text { Casio } \\
\text { Personal-mini** }\end{array}$ & Clear, $1,+,=$,ctc. & 1,3 & 3,8 & 6.9 & 5,7 & $\begin{array}{l}\text { Casio, Inc. } \\
361 \text { County Avenue } \\
\text { Sealtcus. New Jersey }\end{array}$ \\
\hline $\begin{array}{l}\text { J. C. Penney } \\
2310^{* *}\end{array}$ & Clear $1,+, 1=$, cte. & 1,2 & 7,8 & 2.9 & 2,10 & $\begin{array}{l}\text { J. C. Penney } \\
\text { New York, New York }\end{array}$ \\
\hline $\begin{array}{l}\text { Rockwell } \\
\text { International } \\
\text { loRt }\end{array}$ & Clear, $1,+$ etce & 4,8 & 3.8 & 4.5 & & $\begin{array}{l}\text { Rockwell Internitional } \\
805 \text { Lapham Street } \\
\text { lil Segundo, California }\end{array}$ \\
\hline Craig 4511* & Clear $1,+,=, c t c$ & 9,10 & 9,11 & 7,10 & 8,10 & $\begin{array}{l}\text { Craig Corporation } \\
\text { Compton, California }\end{array}$ \\
\hline
\end{tabular}

*The wires from the keyboard are numbered from left to right loohing from the top of the printed circuit board to which the keyboard wires are connected (i.e., the side of the printed circuit board with the number display visible):

**The wires from the keyboard are numbered from top to bottom with the keyboard oriented for ordinary use.

tThe keyboard unplugs from the rest of the calculator. Wires for pluss are located on the left side of the circuit board

(Wires $1,2,3$, and 4 from top to bottom) and bottom of the circuit board (Wires 4 , 5 , 6, 7 , and 8 from left to right). 
REAR VIEW

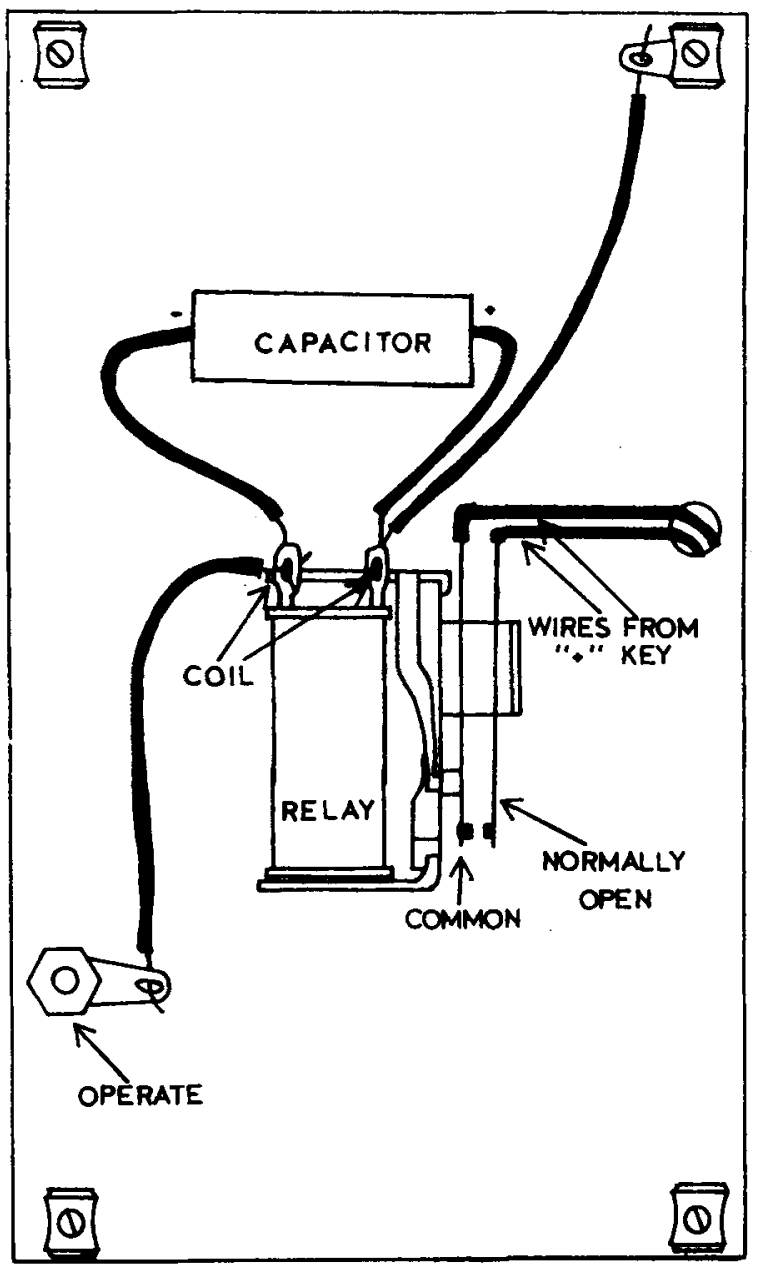

FRONT VIEW

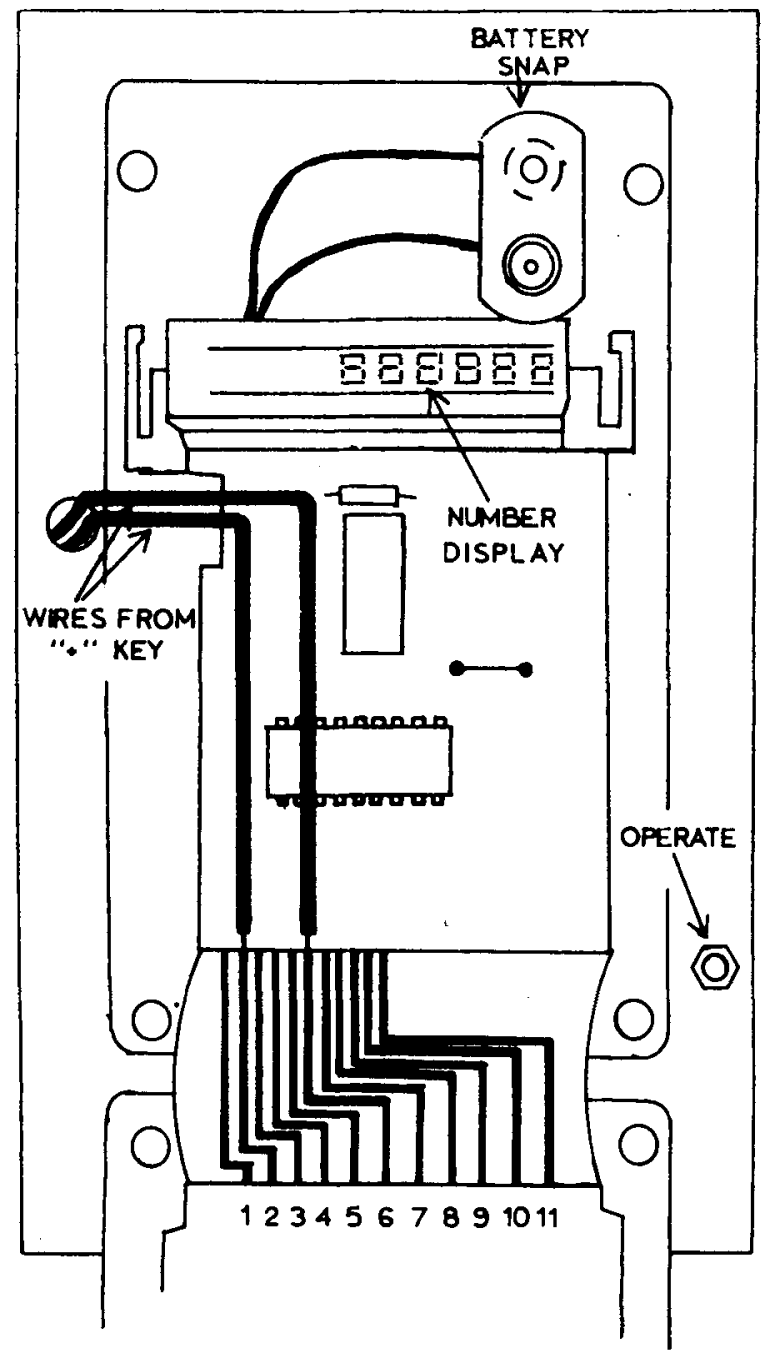

Figure 1. Front and back view of calculator converted into a counter. The calculator (front view) is opened to show connections coming from keyboard.

calculators. The wires are numbered from left to right looking from the top of the printed circuit board, i.e., the side with the number display visible. The table also indicates if the " + " or " $=$ " key must be used for a given calculator. Figure 1 shows a typical calculator-counter conversion; the calculator is a Novus 650. Table 1 and Figure 1 show that wires 2 and 6 are for the " $+"$ key in the Novus 650 . The wires for " $+"$ or " $="$ on calculators other than the six calculators in Table 1 can be determined by systematically shorting two wires at a time on the insulating strip until the calculator performs an addition.

Connect a capacitor across the relay coil. The value for the capacitor (between 5 and $250 \mathrm{mfd}$ at $28 \mathrm{~V}$ or more) depends on the relay used. The capacitor should keep the relay closed for approximately 20 msec. A larger capacitor can be used if it is desirable to temporarily inactivate the counter after each count. Counter operation is as silent as the relay; a reed relay is ideal for the present low-current circuit. The operate stud for the relay can be attached to the front of a piece of Plexiglas that can be snapped onto a programming rack. The operate stud is attached to one side of the relay coil, the side that is attached to the negative side of the capacitor. The other side of the relay coil is connected to the positive side of the power supply through the snaps at the top corners of the Plexiglas. The calculator is glued to the front of the piece of Plexiglas and the relay is mounted on the back of the same piece. The wires soldered to the tlexible strip from the keyboard come out of a small hole notched in the calculator case.

The calculator can be powered by a dc power supply of the same voltage as the calculator's battery. Wires from the power supply can be soldered to the wires 
going to the battery plug in the calculator.

In order to operate the counter, push the keys in the order shown in Table 1. For example, the Exactra 21 requires pushing the "clear" key, entering the number 1 . and using the operate stud from the relay (minus $28 \mathrm{~V}$ ) to enter all additional tallies. It is possible to have an additional relay for resetting the coumer electrically; normally open and common of the relay are connected to the two positions on the flexible strip that go to the clear key. Table 1 shows the wires for the clear key on the six calculators.

The " 1 " can also be entered by relay circuitry that automatically enters " 1 " after the calculator is cleared (see lable 1 for the "l" key on the six calculators). However. we have found that it is very easy to manually clear the counter and enter " 1 " before each operation. Consequently. modification of the cialculator requires only two components, a relay and a capacitor. The counter can be used as a calculator for quick calculations when it is not in use in the described counting operations.

Since the counter starts with the number 1 entered in the display, the total on the counter is one more than the number of times that the operate stud is activated. If a number other than 1 is entered, additional depressions of the " + " (or " $="$ ) key adds the number (constant) that has been entered. For cxample, if 4 is entered in the counter, the counter will cumulate in the sequence $4,8,12,16,20$, etc.

A few calculators are unsuitable for modification because of difficulty in gaining access to the wires from the keyboard. Many Texas Instruments and International Rockwell calculators are in the "more difticult to modify" category. Calculators cited in Table 1 are relatively easy to modify. The units in Table 1 are ranked in terms of ease of modification.

It is possible to put a photodiode across the " + " key, or any other key of the calculator. A change in resistance occurs across the photodiode when a light is switched on and off. A decrease in resistance for the photodiode acts as a switch closure (Alexandrovich, 1975). Our attempts to interface the switch inputs to a calculator with changes in voltage from transistorized or integrated circuits have not been successful. The voltages generated within the calculator chip(s) have been incompatible with our externally introduced voltages.

\section{REFERENCE}

Alexandrovich, SR.. G. Convert your pocket calculator into a programmable counter. Electronic Design. 1975. 23, 100.

(Received for publication March 17. 1975; revision received April 8. 1975.) 